\title{
DETERMINATION OF THE FRICTION COEFFICIENT DURING HOT STRIP ROLLING UNDER INDUSTRIAL CONDITION USING FORWARD SLIP
}

\author{
${ }^{1,2}$ Aleksey SEVIDOV , ${ }^{1,2}$ Aleksandr MUNTIN \\ 'Vyksa Steel Works, Vyksa, Russia, sevidov ae@vsw.ru \\ ${ }^{2}$ Bauman Moscow State Technical University, Moscow, Russia, muntin av@omk.ru
}

https://doi.org/10.37904/metal.2021.4103

\begin{abstract}
The main purpose of this study is to develop an algorithm for determining the friction coefficient value using actual technological parameters of the hot rolling mill. The presented algorithm is based on Ekelund formula where the friction coefficient is expressed in terms of the roll bite contact geometry, which can be calculated using technological parameters such as forward slip, metal thickness and roll diameter. Processing of this collected data allows us to obtain the friction coefficient based on the rolling of several thousand strips under the conditions of a hot strip mill 1950. The research results demonstrate how the main technological factors affect the friction coefficient value where the roll speed is the most significant correlation factor. Statistical analysis shows that the friction coefficient dataset is very similar to results in the literature, moreover, this method makes it possible to refine them.
\end{abstract}

Keywords: Friction coefficient, hot strip rolling, forward slip

\section{INTRODUCTION}

One of the most popular technology for the production steel strips is the combined process of continuous casting of steel and rolling. Thus, casting and rolling complexes produce about 125 million tons of hot-rolled strips per year in the world, which is up to $30-40 \%$ of such products [1]. The use of combined technology allows to move to the efficient production of ultra-thin strips with a thickness of $0.8-1.5 \mathrm{~mm}$ and to replace cold-rolled strips in some cases [2-4]. However, the successful implementation of the production process for ultra-thin strips directly depends on the level of mathematical and physical models embedded in the automated control system.

Hot rolling of a thin strip is characterized by a high ratio of the contact area $(S)$ to the volume of the deformable metal $(V$. This ratio $S: V$ does not have a direct physical meaning, but clearly shows the features of the contact arc when different thicknesses are rolled. For example, in case of $1 \mathrm{~mm}$ thickness $S: V$ in last stands is about $0.5-0.9$ and in case of $5 \mathrm{~mm}$ is $0.14-0.19$. Accordingly, the effect of friction on the rolling force is significantly increased when thinner gauges are rolled in the last finishing stands.

There is a lot of research in the field of friction analysis during rolling. The generalization of research results of friction forces is presented in the works of Tselikov [5], Panikovich [6]. As a rule, research is conducted in a laboratory. However, key technological parameters, such as diameter of work rolls, speed, force and torque, an amount of surface scale in industrial conditions differ from laboratory conditions. In later works, the authors conduct research under industrial conditions, applying the accumulated fundamental knowledge and real data from technological lines. Example of determining the friction coefficient during hot rolling on the basis of processing technological data are given in [7]. The main purpose of the present work is to determine the friction coefficient during the steady-state process of hot rolling in industrial conditions of casting and rolling complex of Vyksa Steel Works (Russia) [8]. 


\section{FIGURES, EQUATIONS, TABLES}

An ibaPDA system (Process Data Acquisition System) is the core software for different measured data in automated technical processes of the hot strip mill in casting and rolling complex. The technique described below was performed using ibaAnalyzer tool, where analysis procedures can be flexibly created for each rolled coil.

Method of determining the friction coefficient in terms of a forward slip is used to study. For this, we applied the Ekelund formula:

$\mu=\frac{1-\cos \alpha}{\sin \alpha-2 \sin \gamma}$

where $\gamma(\mathrm{rad})$ is the neutral angle, $\alpha$ (rad) is the bite angle, $\mu$ is the friction coefficient. The neutral angle is calculated from the forward slip for the finishing mill stands according to the Dresden formula:

$\gamma=\sqrt{\frac{S \cdot h_{1}}{R}}$

where $S(-)$ is the forward slip, $h_{1}(\mathrm{~mm})$ is the exit thickness of a strip, $R(\mathrm{~mm})$ is the work roll radius. The forward slip value can be expressed by the relation:

$S=\frac{\vartheta_{1}-\vartheta_{0}}{\vartheta_{0}}$

where $\vartheta_{0}(\mathrm{~m} / \mathrm{s})$ is the work roll peripherical speed measured with high precision, $\vartheta_{1}(\mathrm{~m} / \mathrm{s})$ is unmeasured exit speed of a strip. However, it is possible to calculate the actual speed of a strip using the distance between finishing stands $L(\mathrm{~m})$ and the time of passing a strip $T(\mathrm{~s})$ from one stand to another:

$\vartheta_{1}=\frac{L}{T}$

where $L=5500 \mathrm{~mm}$ for all finishing stands. Time of passing a strip $T$ is determined by the metal in stand signal, which is calculated with measurements of the drive power loads and the rolling force. The bite angle $\alpha$ is determined from equation:

$\cos \alpha=1-\frac{\Delta h}{D}$

Where $D(\mathrm{~mm})$ is the work roll diameter. The evaluation of the actual draft $\Delta h(\mathrm{~mm})$ is carried out using the hot strip mass flow, which is described as follows:

$\vartheta_{i} \cdot F_{i}=$ const

where $i$ is the number of stand, $F_{i}\left(\mathrm{~mm}^{2}\right)$ is the profile area. In this case, the strip width can be neglected, since even with the largest reduction in the finishing group, the increase in width is less than $1 \%$.

Further, an automated software package has been created that implements the algorithm for processing the measured technological parameters in accordance with the proposed technique. All necessary calculations are performed in the ibaAnalyzer environment.

The presented technique was applied for 14,000 coils of various gauges rolled at a hot strip mill. Figure 1 shows histograms of the friction coefficient values distribution. Obtained data is calculated by the proposed method for 490 strips of ST2PS steel grade and thickness less than $1.5 \mathrm{~mm}$. The rolling process of the presented gauge is characterized by a high speed (up to $10 \mathrm{~m} / \mathrm{s}$ ) and an increased metal flow in the longitudinal 
direction at the end section of the strip head, that is, the method error for ultra-thin strips is the highest. For stands F1, F2 and F3, distributions have a small dispersion, and the average value can be determined quite clearly. The dispersion increases for stands F4 and F5, there is a characteristic "tail" to the area of increased values, but the nature of the distribution allows the use of average values in case of a large number of measurements.

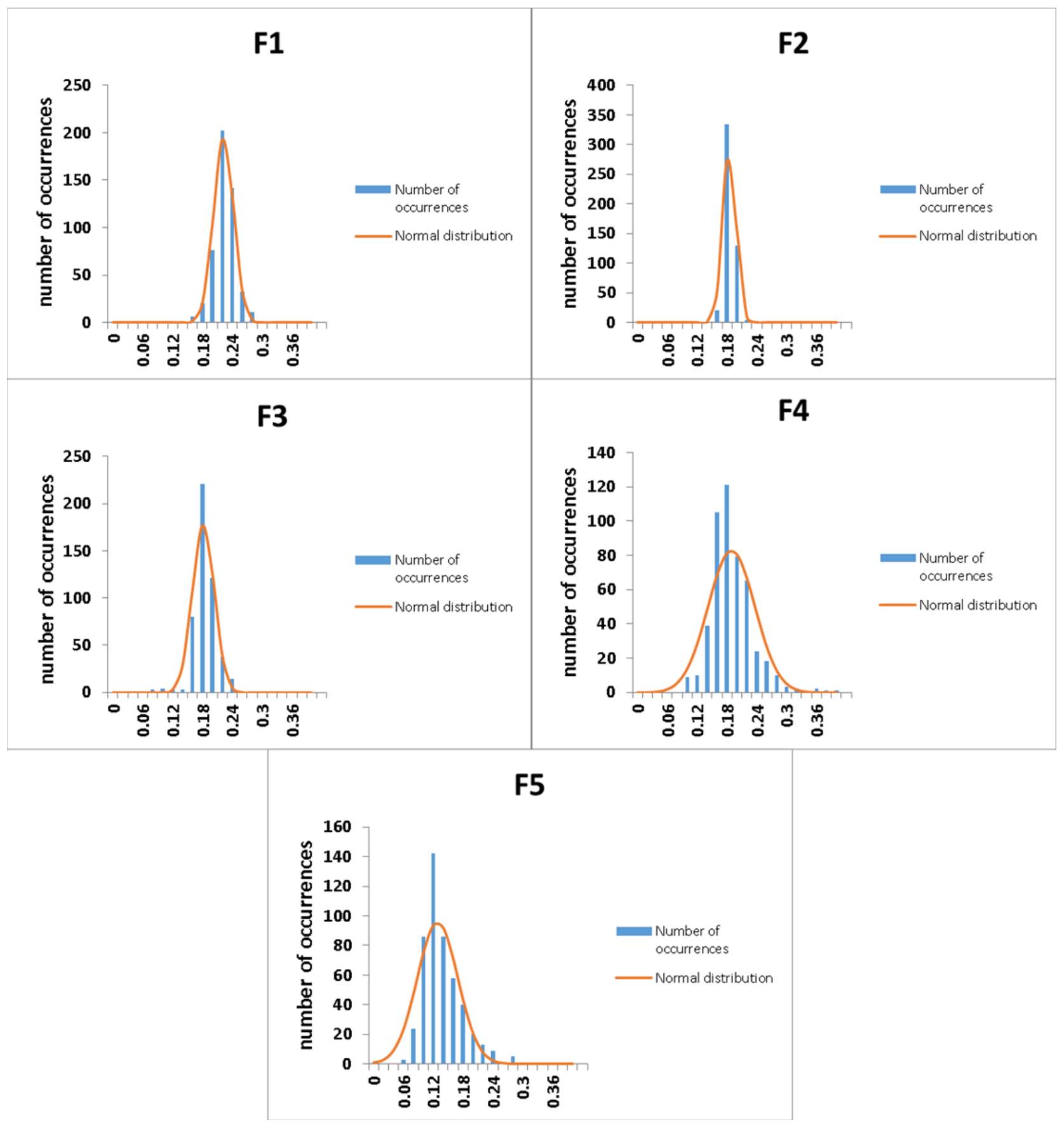

Figure 1 Distribution of the obtained value of the friction coefficient for the stands of the finishing group F1-F5

Average values of the friction coefficients according to calculations for three different grades position (medium carbon steel 22GU, low-alloy strips K56 and low-carbon ultrathin gauge ST2PS) are shown in Table 1. 
Table 1 Average values of temperature $T$, strain $\mathcal{E}$, roll speed $V$, obtained friction coefficient $\mu$, standard deviation $\operatorname{STD}(\mu)$.

\begin{tabular}{|c|c|c|c|c|c|c|c|}
\hline Steel Grade & $\begin{array}{c}\text { Thickness } \\
(\mathrm{mm})\end{array}$ & Stand & $\begin{array}{c}T \\
\left({ }^{\circ} \mathrm{C}\right)\end{array}$ & $\mathcal{\varepsilon}$ & $\begin{array}{c}V \\
(m / s)\end{array}$ & $\mu$ & $S T D(\mu)$ \\
\hline \multirow{5}{*}{ 22GU } & & $\mathrm{F} 1$ & 986.10 & 0.45 & 0.75 & 0.32 & 0.04 \\
\hline & & $\mathrm{F} 2$ & 958.56 & 0.36 & 1.08 & 0.23 & 0.02 \\
\hline & 8 & F3 & 930.65 & 0.32 & 1.48 & 0.26 & 0.04 \\
\hline & & $\mathrm{F} 4$ & 905.87 & 0.21 & 1.88 & 0.22 & 0.04 \\
\hline & & F5 & 881.25 & 0.18 & 2.24 & 0.19 & 0.05 \\
\hline \multirow{5}{*}{ K56 } & \multirow{5}{*}{8} & $\mathrm{~F} 1$ & 947.36 & 0.47 & 0.87 & 0.28 & 0.03 \\
\hline & & $\mathrm{F} 2$ & 925.79 & 0.34 & 1.23 & 0.27 & 0.04 \\
\hline & & F3 & 902.93 & 0.29 & 1.65 & 0.28 & 0.07 \\
\hline & & $\mathrm{F} 4$ & 882.89 & 0.21 & 2.05 & 0.28 & 0.05 \\
\hline & & F5 & 863.73 & 0.17 & 2.41 & 0.23 & 0.07 \\
\hline \multirow{5}{*}{ ST2PS } & \multirow{5}{*}{1.3} & $\mathrm{~F} 1$ & 957.31 & 0.94 & 1.01 & 0.21 & 0.02 \\
\hline & & $\mathrm{F} 2$ & 914.21 & 0.74 & 2.08 & 0.17 & 0.01 \\
\hline & & F3 & 871.95 & 0.59 & 3.63 & 0.17 & 0.02 \\
\hline & & $\mathrm{F} 4$ & 840.86 & 0.36 & 5.39 & 0.18 & 0.05 \\
\hline & & F5 & 817.29 & 0.31 & 7.50 & 0.12 & 0.04 \\
\hline
\end{tabular}

Analyze of calculation results showed that the working layer of high chrome cast iron F1-F2 (Table 2) has a lower friction coefficient as compared to stands F3-F5.

Table 2 Chemical composition of the working layer of the finishing work rolls.

\begin{tabular}{|c|c|c|c|c|c|c|c|c|c|c|c|c|c|c|}
\hline \multirow{3}{*}{ Stand } & \multicolumn{14}{|c|}{ Chemical composition } \\
\hline & \multicolumn{2}{|c|}{ C } & \multicolumn{2}{|c|}{ Si } & \multicolumn{2}{|c|}{ Mn } & \multirow{2}{*}{$\begin{array}{c}\mathbf{P} \\
\max \end{array}$} & \multirow{2}{*}{$\begin{array}{c}S \\
\max \end{array}$} & \multicolumn{2}{|c|}{$\mathrm{Cr}$} & \multicolumn{2}{|c|}{ Mo } & \multicolumn{2}{|c|}{$\mathrm{Ni}$} \\
\hline & $\min$ & $\max$ & $\min$ & $\max$ & $\min$. & $\max$ & & & $\min$ & $\max$ & $\min$ & $\max$ & $\min$ & $\max$ \\
\hline $\mathrm{F} 1-\mathrm{F} 2$ & 2.40 & 3.40 & 0.50 & 1.20 & 0.50 & 1.40 & 0.10 & 0.06 & 16.00 & 22.00 & 1.00 & 1.50 & 1.00 & 2.00 \\
\hline F3-F6 & 3.00 & 3.40 & 0.50 & 1.20 & 0.50 & 1.20 & 0.10 & 0.04 & 1.20 & 2.00 & 0.20 & 0.60 & 3.80 & 4.80 \\
\hline
\end{tabular}

Zaykov et al. generalized experimental data of various researchers in their book [9] and illustrated the effect of the rolling speed from 0 to $16 \mathrm{~m} / \mathrm{s}$ on the friction coefficient during passing into roll bite. The authors describe all experimental data as a single curve characterized by the following equation:

$\mu_{\mathrm{e}}=\frac{0.43}{V_{r}^{0.225}}$

where $\mu_{\mathrm{e}}$ is the friction coefficient during initial entry of the workpiece into the roll bite, $V_{r}(\mathrm{~m} / \mathrm{s})$ is the work roll peripherical speed. 
In this case, the friction coefficient for a steady-state process is more often determined as [10]:

$\mu_{s}=0.6 \cdot \mu_{\mathrm{e}}$

where $\mu_{s}$ is the steady-state friction coefficient.

There are three lines in the Figure 2: the orange one is the friction coefficient during initial entry of the workpiece into the roll bite according to formula (7), the gray one is the friction coefficient for a steady-state process according to formula (8) and the blue one is the line of points obtained by the authors.

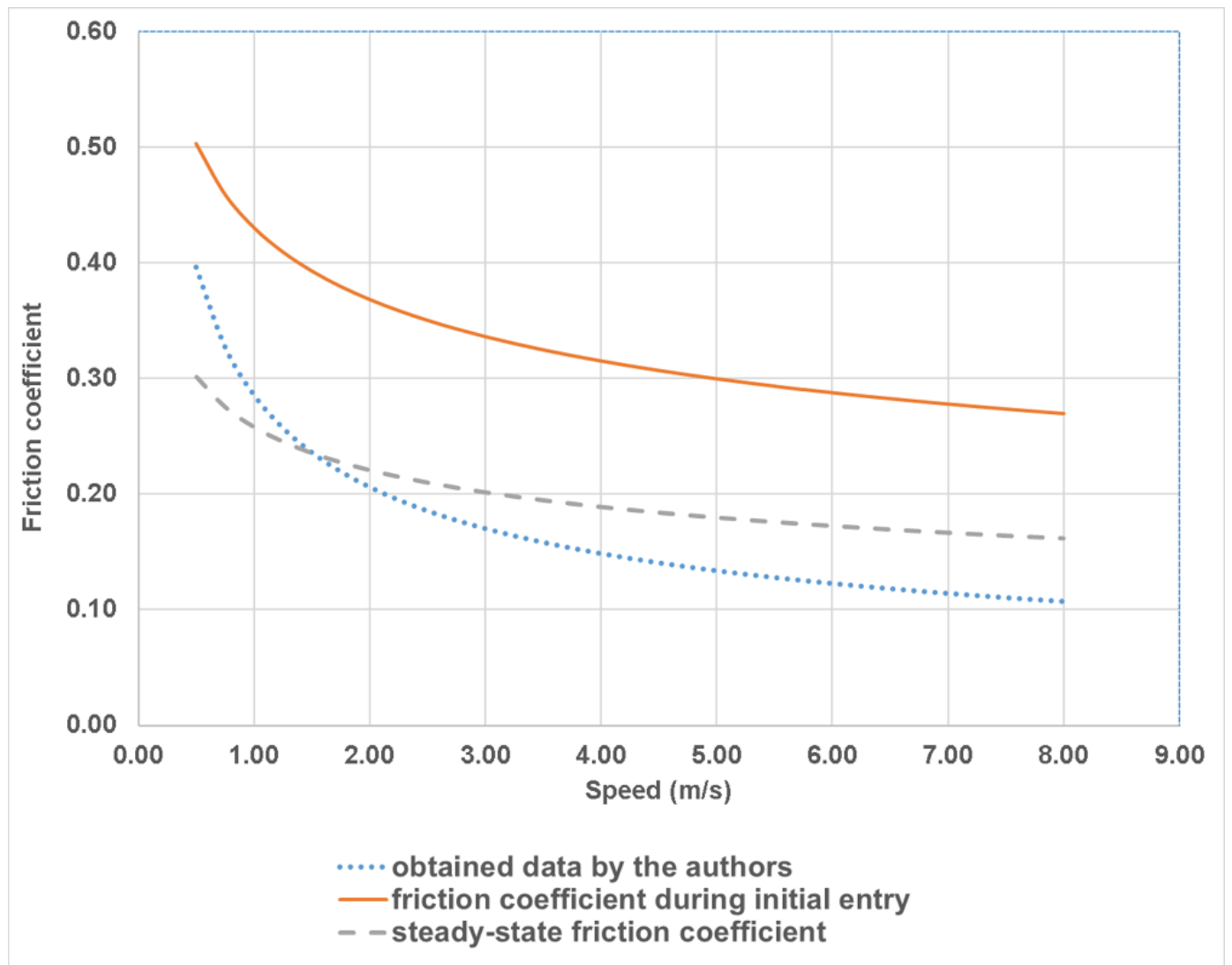

Figure 2 Comparison of the obtained data with the theoretical friction coefficient

The fact is the ratio $\frac{\mu_{\mathrm{e}}}{\mu_{\mathrm{s}}}$ is not a constant value. It depends on the speed and can be described by following equation:

$\frac{\mu_{\mathrm{e}}}{\mu_{\mathrm{s}}}=1.5 \cdot V_{r}^{0.25}$

Analysis of the friction coefficient on technological parameters shows that the temperature has a weak effect on the change in friction coefficient for the first two stands. However, the strain and rolling speed have a strong relation with the experimental value of friction coefficient (Figure 3). A similar pattern is observed for indefinite rolls F3-F5, where speed and strain have the greatest effect on the friction coefficient. Probably, the reason is that the range of rolling temperatures in the finishing mill is relatively small $\left(800-1000{ }^{\circ} \mathrm{C}\right)$. Therefore, the effect of the temperature is difficult to detect for the tested range, especially considering the significant influence of the rolling speed. 


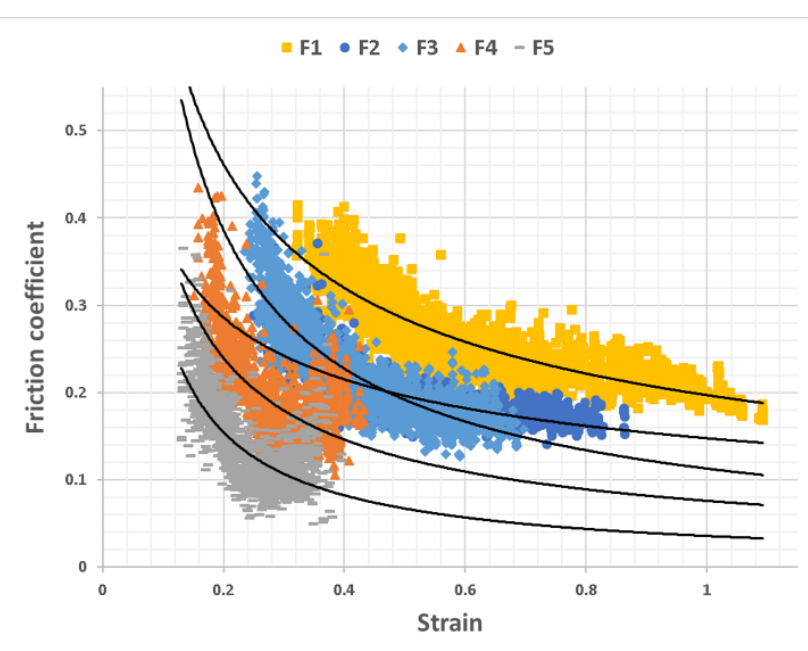

a)

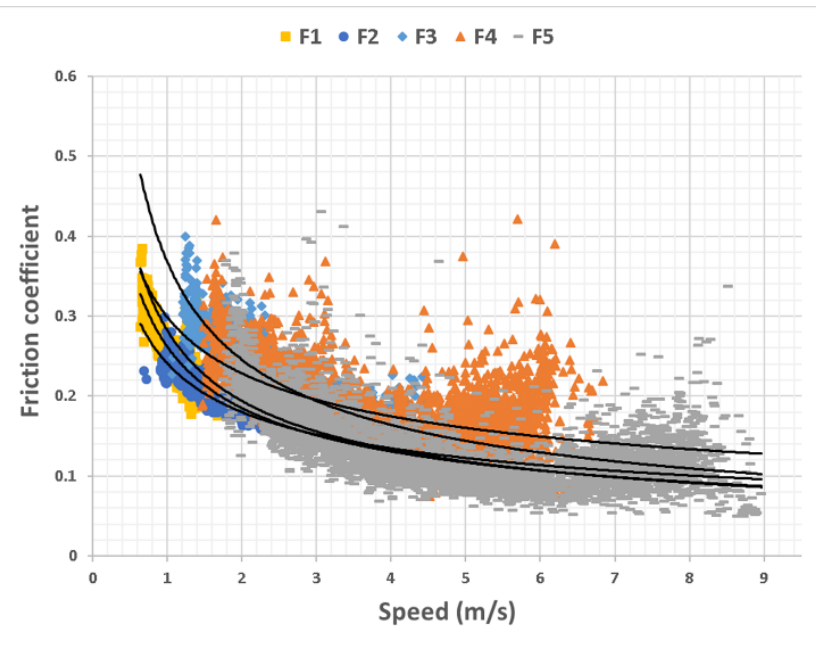

b)

Figure 3. Dependence of the friction coefficient for each stand F1-F5 a) on the degree of deformation b) on speed.

\section{CONCLUSION}

1) Friction forces are essential in the hot rolling process. Accurate estimation of the friction coefficient under industrial conditions allows to improve mathematical models for modern hot-rolling mills. It also positively affects the cost component of a hot rolled strip production.

2) In this study, the method of determining the friction coefficient for a steady-state hot rolling process is proposed and implemented. Algorithm is based on the actual technological parameters obtained from sensors in the finishing mill of casting and rolling complex of Vyksa Steel Works (Russia).

3) The analysis of the friction coefficient values obtained for the finishing stands F1-F5 showed that rolling speed and strain have a greatest impact. No significant effect of the temperature has been found. Probably, it is due to the limited temperature range and strong influence of other factors.

4) Friction coefficients values for the steady-state process were determined for each steel grade produced under conditions of casting and rolling complex. The values are in the range of $0.12-0.32$, where the highest friction coefficient value is typical for the first stands F1-F2, and lowest values are found for thinner gauges produced at a high speed.

5) The influence of the working layer of the work rolls on the friction coefficient is demonstrated. Alloy cast iron containing chromium has a lower friction coefficient in contrast to the indefinite cast iron, which is used for the working layer of the last finishing stands. This aspect makes it possible to predict in advance the behavior of the metal in the finisher stands.

\section{REFERENCES}

[1] MUNTIN, A.V. Advanced technology of combined thin slab continuous casting and steel strip hot rolling. Metallurgist. 2019, vol. 62. pp. 900-910.

[2] MUNTIN, A.V., KURENKOV, YU.M., KOLESNIKOV, A.G. Contemporary production solutions and equipment for manufacturing ultrathin hot-rolled strip. Proizvod. Prokata. 2016, no. 8, pp. 13-21.

[3] QIN, Z., YU, Y., ZHAO, W. Development and Application of ESP Products in Rizhao Steel. Ibid. 2018 , pp. 49-58.

[4] PIGANI, A., BOBIG, P., KNIGHTS, M., MARTINIS, S. Danieli Universal Endless (DUE). Berg Huettenmaenn Monatsh. 2016, vol. 161, pp. 429-439.

[5] TSELIKOV, A.I., TOMLENOV, A.D., ZUZIN, V.I., (eds.). Rolling theory handbook. Moscow: Metallurgy (in Russian), 1982. 
[6] PANJKOVIC, V. Friction and the Hot Rolling of Steel. Boca Raton: Taylor \& Francis, 2014.

[7] GORNI, A.A., SOARES DA SILVA, M.R. Characterization of the friction conditions in the finishing stands of a hot strip mill. Technology in Metallurgy, Materials and Mining. 2012, vol. 9, no. 2, pp. 103-108.

[8] LAMUKHIN, A.M., DUBININ, I.V. Startup of a casting-rolling complex and mastery of the production of highquality rolled products for electric-welded pipes. Metallurgist. 2010, vol. 54, no 1-2, pp. 19-27.

[9] ZAYKOV, M.A., POLUKHIN, V.P., ZAYKOV, A.M., SMIRNOV, L.N. Process of rolling. Moscow: MISIS, 2004.

[10] KRIVENTSOV, A.M. Friction coefficient at hot, cold and warm rolling of non-ferrous and ferrous metals. Construction, calculation and research of rolling mills: collection of scientific works. Moscow: VniiMetMash, 1987. pp. 75-81. 